Article

\title{
An Approach for Evaluating the Influence of Accessibility on Offshore Wind Power Generation
}

\author{
Mian Du ${ }^{1}$,,${ }^{*}$, Jun $\mathrm{Yi}^{2}$, Peyman Mazidi ${ }^{3}$, Lin Cheng ${ }^{1}$ and Jianbo Guo ${ }^{2}$ \\ 1 Department of Electrical Engineering, Tsinghua University, Beijing, Haidian, 100084, China; \\ chenglin@mail.tsinghua.edu.cn \\ 2 China Electric Power Research Institute, Beijing, Haidian, 100192, China; yjun@epri.sgcc.com.cn \\ guojb@epri.sgcc.com.cn \\ 3 Department of Electric Power and Energy Systems (EPE), KTH Royal Institute of Technology, Stockholm, \\ Sweden; mazidi@kth.se \\ * Correspondence: dm13@mails.tsinghua.edu.cn; Tel.: +86-188-1060-6260
}

\begin{abstract}
For offshore wind power generation, accessibility is one of the main factors that has great impact on operation and maintenance due to constraints on weather conditions for marine transportation. This paper presents a framework to explore the accessibility of an offshore site. At first, several maintenance types are defined and taken into account. Next, a data visualization procedure is introduced to provide an insight into the distribution of access periods over time. Then, a rigorous mathematical method based on finite state Markov chain is proposed to assess the accessibility of an offshore site from the maintenance perspective. A five-year weather data of a marine site is used to demonstrate the applicability and the outcomes of the proposed method. The main findings show that the proposed framework is effective in investigating the accessibility for different time scales and is able to catch the patterns of the distribution of the access periods. Moreover, based on the developed Markov chain, the average waiting time for a certain access period can be estimated. With more information on the maintenance of an offshore wind farm, the expected production loss due to time delay can be calculated.
\end{abstract}

Keywords: accessibility; offshore; operation and maintenance; weather condition; Markov chain; data visualization

\section{Introduction}

Since Vindeby [27], the first offshore wind farm that was built in 1991 in Denmark, the world has witnessed a big step in the development of offshore wind industry. By the end of 2015, the worldwide installed offshore wind power capacity was more than 12 GW [1], and there are plans to install more in the future.

However, after the wind turbines are installed offshore, maintaining them are significantly harder than maintaining onshore wind turbines. There are several factors that cause the offshore maintenance tasks be more difficult, costly and time consuming than onshore maintenance. Among these factors, the accessibility of an offshore wind farm brings more uncertainty to decision making and execution of maintenance strategies. Due to the weather status, the accessible periods to an offshore site are often limited. Hence, for a certain type of maintenance, a matching accessible period is not always available at the moment and the operator may need to wait for a relatively long time. This delay reshapes almost all the schedules related to logistic, organization and maintenance. Moreover, it will reduce the production if the wind source during the delay is good. For offshore wind farms, wave heights and wind speeds are the main characters considered in the published works on accessibility study [2-4].

The concept of accessibility can be widely noticed in the fields of land use, transportation, biology and information web [5-8]. It is used to describe the available paths between the point of departure and the destination and the ease of reaching there. For designing and operation stages, the 
findings from the fields of land use and transportation are more practical to be applied in accessibility investigation of offshore sites. However, for accessibility of offshore sites, the main concern is often related to the safety of transferring technicians and working conditions [3]. In other words, the accessibility issue causes a delay where the demand for maintenance cannot be satisfied in time. The issues raised in this paper are not limited to one offshore site and can be considered as reference for the other offshore sites such as wave energy and offshore floating drilling.

As for offshore wind energy, research works related to accessibility issues can be broadly divided into three categories. The first area is optimization work on maintenance support and logistic. In [12], an optimal model for offshore maintenance scheduling and vessels routing is proposed, in which multiple wind farms, multiple vessels, multiple periods and multiple Operation \& Maintenance (O\&M) bases are taken into account. Dalgic et al. [13] used a time domain Monte-Carlo simulation approach to achieve the most cost-effective approach to allocate O\&M resources as transport vehicles. They also analyzed the environmental conditions such as wind speed, wave height, and wave period. Stalhane et al. [15] proposed a two-stage stochastic model to optimize fleet size and mix of vessels for offshore maintenance considering uncertainty from both demand and weather conditions. In addition, since helicopter also plays an important role in offshore wind farm maintenance, authors in [16] used a statistical method to study the helicopter access problem to gain a practical knowledge on the limits of the helicopter operation.

The second area is maintenance strategy optimization. In [9], Bersnard et al. developed a mathematical model for offshore wind farm maintenance optimization, in which the accessibility issue is considered as a time delay. Byon and Ding [10,11] proposed an optimal PM strategy for offshore wind turbines considering the seasonal weather conditions. They assumed that maintenance should be conducted strictly under certain weather conditions. Rademakers et al. [23] optimized the O\&M strategy considering the main factors of availability of standby parts, extreme weather circumstances and crane readiness. Utne [24] proposed a framework to make the maintenance activities more efficient for deep-sea wind turbines. Although the mentioned studies provide costeffective maintenance strategies or logistic plans, the accessibility issue has not been well addressed as most of the studies consider it as a simply time delay. Other features of accessibility, like the pattern of the access periods distribution is one of main factors which determines how long the maintenance crews have to wait before the offshore wind farm is accessible.

The last area, yet a very important one, is the accessibility itself. To ensure high availability of offshore turbines and other offshore renewable energy sites, rapid on-site repairs and equipment function recovery is required. Therefore, it is very important to improve the accessibility level of critical devices and the accessibility for offshore sites. Another reason for quantifying access levels is economics. Dalton [25] claims that a more detailed study is needed to determine the service time of the equipment, as well as the weather window before a more reliable estimate of the cost of the wave energy project can be safely evaluated. In [26] the cost impact of weather windows deployed at wave stations in UK test stations is assessed. The main conclusion is that the primary factor that influence capital expenditure is downtime related to weather conditions. A comprehensive understanding of the weather window is essential on both planning and operation stages. O'Connor et al. [2] analyzed Irish west coast wave data related to O\&M of marine renewables. In this work, a comprehensive statistical results of access periods in this area are provided. Martins et al $[3,4]$ analyzed weather windows of a site off Portugal coast considering significant wave height and wind speed. They also used curve fitting techniques to gain an insight into the patterns of the distributions of weather windows. Moreover, Martini et al. [14] assessed the accessibility of offshore wind farms in the North Sea based on light and heavy repair operations. They provide mathematical definitions for several concepts like weather window, approachability, accessibility and waiting periods.

Motivated by the previous works on accessibility of offshore wind farms, this paper is trying to take a small step forward to tackle some issues which are partially settled. The first is historical accessibility data visualization. Access periods distribute over time and space. While the authors in [14] investigated the distribution of access periods in a certain area for a certain offshore wind farm, the distribution over time is also very important and can be used as reference for maintenance 
scheduling. The second is accessibility assessment. As in [3] and [14], the authors create several parameters to assess the accessibility of a certain site. However, from the perspective of an offshore wind farm operator, accessibility is an uncertainty factor which pulls up the budget on O\&M. In this paper, an economic index based on Markov chain is created to quantify the influence that accessibility has on extra maintenance costs.

The rest of this paper is organized in the following way. In section 2, an overview on access issues raised by transfer vessels and helicopters are provided. Then the methods used in this paper are introduced in detail. In section 3, a case study with a 5-year marine weather data is represented and the results are discussed carefully. Then the main findings in this paper are summarized in section 4 and the future work is pointed out.

\section{Methodology}

\subsection{Overview}

The significant wave height (WH) and wind speed (WS) are the widely used references in accessibility studies due to their great impact on the safety of marine transportation and landing. According to [2], the limits of accessibility to an offshore wind farm due to significant wave height for different transportations are presented in Table 1.

Table 1 Access limits for different transportation types due to WH and WS

\begin{tabular}{ccc}
\hline Transportation Types & WH limit $(\mathrm{m})$ & WS limit $(\mathrm{m} / \mathbf{s})$ \\
\hline Conventional vessel & $1.5 \mathrm{~m}$ & $/$ \\
Catamaran & $1.5-2 \mathrm{~m}$ & $/$ \\
SWATH vessel & $2.5 \mathrm{~m}$ & $/$ \\
Ampelmann & $3 \mathrm{~m}$ & $/$ \\
Helicopter & $/$ & 15 \\
\hline
\end{tabular}

However, as for O\&M of an offshore wind farm, the access periods defined only by weather conditions are not appropriate to be used in real cases. Considering Table 2 which provides information on the time window that a certain maintenance type needs [17], the effective access periods should be at least longer than the minimum required time for maintenance tasks. Even though the access time varies along with the distance that a wind farm is off the coast, in this paper, only the time windows which are longer than 6 hours are considered as effective access periods.

Table 2 Time required for different types of maintenance

\begin{tabular}{cccc}
\hline Maintenance type & Maintenance Time (hrs) & Access Time (hrs) & Maintenance Description \\
\hline 5 & 3 & 3 & Inspection \\
4 & 3 & 3 & Minor repair \\
3 & 10 & 3 & Major repair \\
2 & 50 & 3 & Partial replacement \\
1 & 70 & 3 & Complete replacement \\
\hline
\end{tabular}

\subsection{Historical Accessibility Data Visualization}

To provide a general frame of this subsection, we divide it into 4 parts to show a comprehensive exploration on accessibility of an offshore site.

\subsubsection{Annul accessibility and constitution}

Annul accessibility is defined as the coverage of all access periods in a year. Then based on the typical length of the access periods, the constitution of annul accessibility is provided to show the effective access time windows that are available in a year. 
Usually the access periods only take weather conditions into account. For an offshore wind farm, it is not preferable to turn off the wind turbines for a scheduled overhaul when the wind resource is good. Moreover, access periods with medium length are desirable when the wind turbines are fully functioning as potential risk can be diminished in time with no production loss.

To investigate the joint distribution of wind resource and access periods, inspired by [18], a common measurement of wind power available in an area is expressed as.

$$
p_{W}=\frac{1}{2} Q \times v_{W}^{3}\left(W / m^{2}\right)
$$

In which, $\mathrm{Q}$ represents air density at standard atmosphere $\left(\mathrm{kg} / \mathrm{m}^{3}\right)$ and $v_{W}$ is wind velocity $(\mathrm{m} / \mathrm{s})$.

After calculating the wind resource (WR) in a whole year with equation (1), the daily wind resource is graded in the following way, Table 3 . Then, the joint distribution of daily wind resource and access periods are provided.

Table 3. Criterions for wind resource classification

\begin{tabular}{ccc}
\hline Classifications & Percentage of Max WR & Grades \\
\hline 1. & $/$ & 0 \\
2. & $2 \%$ to $20 \%$ & 1 \\
3. & $20 \%$ to $40 \%$ & 3 \\
4. & $40 \%$ to $60 \%$ & 5 \\
5. & $60 \%$ to $80 \%$ & 7 \\
6. & $80 \%$ to $100 \%$ & 9 \\
7. & $100 \%$ & 10 \\
\hline
\end{tabular}

2.2.3 The distribution of access periods over time

The study on the distribution of access periods over time is the core in this paper. The statistical analysis will provide an insight into the patterns on how the access periods are distributed in a certain period. The results in this part is the basis for accessibility assessment in subsection 2.3. The data analysis procedure is shown in Figure 1.

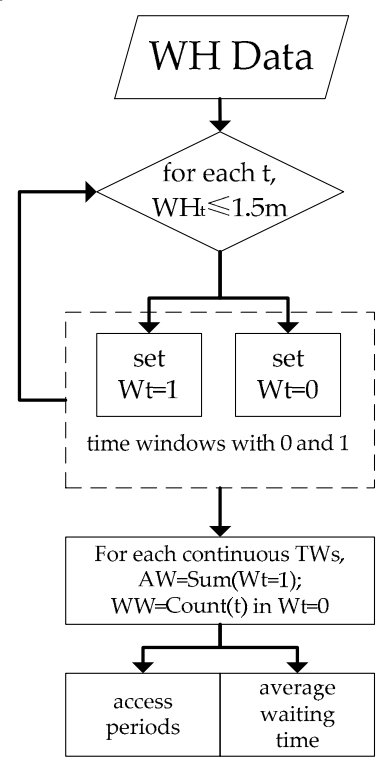

Figure 1. The calculation procedure of access periods with time

In Figure 1, TW represents time window, AW means accessible window and WW denotes waiting window.

2.2.4 Special weather condition 
For marine operation, personnel safety should be duly considering throughout all stages. In some areas, there are special weather conditions which are not considered as main constraints for access periods but may cause serious harm to people's health. Hence, criterions based on special weather condition and corresponding human perception need to be settled. Methods to address this issue need high attention.

\subsection{Markov model for accessiblity assessment}

In this subsection, a finite state Markov chain (MC) is used to portray the patterns of access periods distribution. MC has the ability to feature a preview of future situation if system continues with current considerations; therefore, providing an insight on both past and future weather conditions. From the observed states and their sequences, Transition Probability Matrix (TPM) and Initial State Probability (ISP) of each state can be calculated for the WT. TPM and ISP are demonstrated as:

$$
\begin{gathered}
\text { TPM }=\left[p_{i j}\right]_{n \times n} \\
I S P=\left[q_{1}, q_{2}, \ldots, q_{n}\right]_{1 \times n}
\end{gathered}
$$

where $p_{i j}=P\left(S_{j} \mid S_{i}\right)$ and $q_{i}=P\left(S_{i}\right)$. TPM presents the probability of moving from one state to the other whereas ISP represents probability of being at each state in the beginning.

Considering a finite state Markov model with $\mathrm{n}$ states, the problem is to calculate the average steps to reach state $j$ for the first time from a given state $i$. Assume that the TPM is shown as below,

$$
T P M=\left(\begin{array}{ccc}
p_{11} & \cdots & p_{1 n} \\
\vdots & \ddots & \vdots \\
p_{n 1} & \cdots & p_{n n}
\end{array}\right)
$$

The mathematical definition of the problem can be expressed as:

$$
P_{i j}^{n} \stackrel{\text { def }}{=} P\left(X_{n}=j \mid X_{0}=i\right) \quad i \neq j
$$

in which $P_{i j}^{n}$ means the probability that the state changes to $\mathrm{j}$ for the first time after $\mathrm{n}$ step.

As state $j$ should not be observed until $X_{n}$ in the state sequence, $k$ is used to represent other states in the sequence. From the transition matrix above, the probability of transiting from other states to state $j$ can be expressed as:

$$
P_{k j}=\sum_{k=1}^{n} p_{k} \cdot p_{k j} \quad k \neq j
$$

Then, equation (5) can be rewritten as:

$$
P_{i j}^{n}=\left(1-p_{i j}\right) \cdot\left(1-P_{k j}\right) \cdot\left(1-P_{k, j}\right) \ldots \cdot\left(1-P_{k j}\right) \cdot P_{k j}=\left(1-p_{i j}\right) \cdot\left(1-P_{k j}\right)^{n-2} \cdot P_{k j}
$$

Hence, the probability of first reaching state $\mathrm{j}$ after $\mathrm{n}$ steps from other states can be expressed as:

$$
T P_{i j}^{n}=\sum_{i=1}^{n} P_{i j}^{n}=\left(1-P_{k j}\right)^{n-2} \cdot P_{k j} \cdot \sum_{i=1}^{n}\left(1-p_{i j}\right) \quad i, k \neq j
$$

in which, $T P_{i, j}^{n}$ means the total probability that the state changes to $j$ at $\mathrm{n}$ step.

While,

$$
\sum_{i=1}^{n}\left(1-p_{i j}\right)=\left(1-P_{k j}\right) \quad i, k \neq j
$$

Then, equation (8) can be expressed as:

$$
T P_{i j}^{n}=\left(1-P_{k j}\right)^{n-1} \cdot P_{k j} \quad i, k \neq j
$$

Defining the average steps to change to state $j$ as $N_{\text {average, }}$ it can be expressed as: 


$$
N_{\text {average }}=\sum_{n \geq 1} n \cdot T P_{i j}^{n}=\sum_{n \geq 1} n \cdot\left(1-P_{k j}\right)^{n-1} \cdot P_{k j} \quad i \neq j
$$

Since,

$$
\sum_{n \geq 1} n \cdot s^{n-1}=1+2 s+3 s^{2}+\cdots+n s^{n-1}=\frac{1}{(1-s)^{2}}
$$

Then,

$$
N_{\text {average }}=\frac{P_{k j}}{\left(1-\left(1-P_{k j}\right)\right)^{2}}=\frac{1}{P_{k j}}
$$

Therefore, $N_{\text {average }}$ can be easily calculated after the transition probability matrix is found.

\section{Case Study}

\subsection{Data Source Discription}

The data source is available online [19], the measurement location is at (26.968N 96.694W), Gulf of Mexico. The distance to the nearest coast is around 60 to $70 \mathrm{~km}$. The original data set contains 13 parameters showing the marine weather condition in detail. In this paper, 3 parameters are selected for accessibility analysis. The parameters and their definition are shown in Table 4.

Table 4. Explanations of the selected parameters

\begin{tabular}{ccc}
\hline Abbreviation & Definition & Unit \\
\hline WSPD & $\begin{array}{c}\text { Wind speed averaged over an eight-minute period for buoys and a } \\
\text { two-minute period for land stations. }\end{array}$ & $\mathrm{m}$ \\
MVHT & $\begin{array}{c}\text { Significant wave height is calculated as the average of the highest one- } \\
\text { third of all of the wave heights during the 20-minute sampling period. } \\
\text { Dew point temperature taken at the same height as the air temperature } \\
\text { measurement. }\end{array}$ & $\mathrm{m} / \mathrm{s}$ \\
DEWP & $\begin{array}{c}\text { Celsius } \\
\text { The data set covers a time range from 2011 to 2015. The value of each parameter is provided }\end{array}$ \\
$\begin{array}{c}\text { every hour. Hence the size of the data set is 43800 } 3 \text { 3. In the pre-process stage, the missing data points } \\
\text { and error data points are replaced by the average value of the data point of one hour before and after. }\end{array}$
\end{tabular}

\subsection{Accessibility visualization}

\subsubsection{Annul accessibility from 2011 to 2015}

Based on the access limits, the annual accessibility for vessels of this area are calculated for each year from 2011 to 2015. Moreover, the average annual accessibility is assessed based on 5 years' data. The results are shown in Table 5. Although with certain transfer systems the WH limit can reach $2.5 \mathrm{~m}$ and $3 \mathrm{~m}$, the WH limit for accessibility study are often set as $1.5 \mathrm{~m}$ or $2 \mathrm{~m}$.

Table 5. Annual accessibility under WH constraints from 2011 2015

\begin{tabular}{c|cccc}
\hline \multirow{2}{*}{ Year } & \multicolumn{4}{|c}{ WH Constraints \& Annual AC (\%) } \\
\cline { 2 - 5 } & $\mathbf{1 . 5} \mathbf{~}$ & $\mathbf{2 ~} \mathbf{~}$ & $\mathbf{2 . 5} \mathbf{~ m}$ & $\mathbf{3 ~ \mathbf { ~ }}$ \\
\hline 2011 & 62.6 & 81.1 & 91.9 & 95.0 \\
2012 & 76.8 & 88.7 & 93.8 & 95.7 \\
2013 & 70.4 & 85.4 & 93.1 & 96.2 \\
2014 & 62.7 & 81.2 & 91.9 & 95.0 \\
2015 & 74.8 & 89.7 & 95.8 & 98.3 \\
Average AC & 69.5 & 85.2 & 93.3 & 96.1 \\
\hline
\end{tabular}


To evaluate accessibility, the time window is one of the key points. Based on maintenance time consumptions, different criterions are created to study the distribution of time tables under the constraint. The distributions of TWs for each year from 2011 to 2015 and the classifications are represented in Table 6.

Table 6. Composition of AC from 2011 to 2015 under certain limits and classifications

\begin{tabular}{c|cccccccccc}
\hline & \multicolumn{2}{|c}{$\mathbf{2 0 1 1}$} & \multicolumn{2}{c}{$\mathbf{2 0 1 2}$} & \multicolumn{2}{c}{$\mathbf{2 0 1 3}$} & \multicolumn{2}{c}{$\mathbf{2 0 1 4}$} & \multicolumn{2}{c}{$\mathbf{2 0 1 5}$} \\
\cline { 2 - 11 } & $\mathbf{1 . 5 m}$ & $\mathbf{2 m}$ & $\mathbf{1 . 5 m}$ & $\mathbf{2 m}$ & $\mathbf{1 . 5 m}$ & $\mathbf{2 m}$ & $\mathbf{1 . 5 m}$ & $\mathbf{2 m}$ & $\mathbf{1 . 5 m}$ & $\mathbf{2 m}$ \\
\hline TW $<6 \mathrm{~h}$ & $55.9 \%$ & $57.9 \%$ & $49.8 \%$ & $47.2 \%$ & $55.7 \%$ & $58.9 \%$ & $55.9 \%$ & $57.9 \%$ & $49.6 \%$ & $49.0 \%$ \\
$6 \mathrm{~h}<\mathrm{TW}<24 \mathrm{~h}$ & $20.4 \%$ & $21.5 \%$ & $24.4 \%$ & $25.3 \%$ & $16.3 \%$ & $12.7 \%$ & $20.4 \%$ & $21.5 \%$ & $21.5 \%$ & $11.8 \%$ \\
$1 \mathrm{~d}<\mathrm{TW}<7 \mathrm{ds}$ & $23.4 \%$ & $19.3 \%$ & $22.9 \%$ & $23.4 \%$ & $23.1 \%$ & $20.9 \%$ & $23.4 \%$ & $19.3 \%$ & $23.0 \%$ & $26.5 \%$ \\
$1 \mathrm{w}<\mathrm{TW}<2 \mathrm{ws}$ & $0.38 \%$ & $1.34 \%$ & $3.23 \%$ & $4.46 \%$ & $4.43 \%$ & $4.43 \%$ & $0.38 \%$ & $1.3 \%$ & $3.0 \%$ & $7.8 \%$ \\
$\mathrm{TW}>2 \mathrm{ws}$ & 0 & 0 & 0 & 0 & $4.9 \%$ & $3.16 \%$ & 0 & 0 & $3.0 \%$ & $4.9 \%$ \\
\hline
\end{tabular}

For the limits of WH as $1.5 \mathrm{~m}$ and $2 \mathrm{~m}$, the compositions of AC with different TWs are shown as Figure 2. Although the accessibility under the limit of $\mathrm{WH}$ as $1.5 \mathrm{~m}$ reaches $74.8 \%$ in 2015 , the compositions however, are taken over by TWs which are less than 6 hours. Considering time demand for different maintenance types in Table 2, TWs less than 6 hours are not preferable in practice unless the offshore wind farm has a platform to host technicians, which can save the time for marine transportation.

Considering the WS constraint presented in Table 1, vessels are forbidden to sail when WH exceeds the limit. In this case, only helicopter is available. Accessibility with a helicopter as transportation method is studied as well and the results are presented in Table 7.

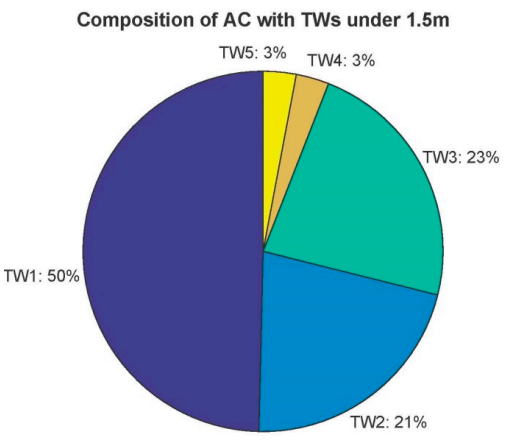

(a)

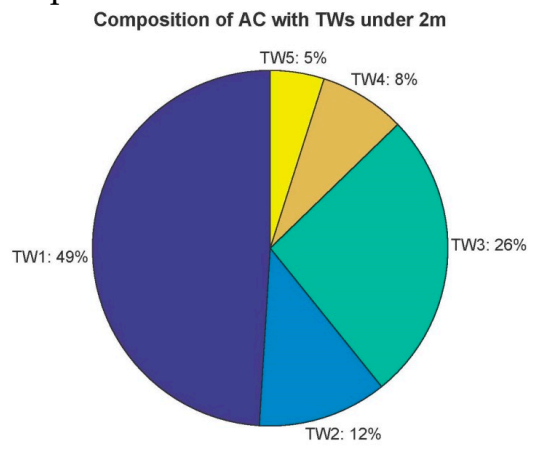

(b)

Figure 2. Composition of AC with defined TWs in 2015

Table 7. Annual Accessibility from 2011 to 2015 with Helicopter

\begin{tabular}{l|llllr}
\hline & $\mathbf{2 0 1 1}$ & $\mathbf{2 0 1 2}$ & $\mathbf{2 0 1 3}$ & $\mathbf{2 0 1 4}$ & $\mathbf{2 0 1 5}$ \\
\cline { 2 - 6 } & \multicolumn{4}{|c}{ Access limit of wind speed is } & $\mathbf{1 5 m} / \mathbf{s}$ \\
\hline Accessibility (\%) & 99.77 & 99.83 & 99.74 & 99.60 & 99.54 \\
Average AC (\%) & \multicolumn{5}{c}{99.69} \\
\hline
\end{tabular}

According to the results, accessibility with helicopter is much higher compared with vessels. However, since the rent of a helicopter is expensive and less crews can be transferred to the offshore wind farm, helicopters are often considered as compensate or emergent choices. Moreover, helicopter transportation is limited by visibility, which should be investigated with more detailed weather data. In this data set, the visibility data is considered perfect for the helicopter.

\subsubsection{Access periods considering wind resource}

The concept of accessibility is more general than just considering weather conditions as constraints. Wind resource is one of the most important factors during a planning stage for choosing an offshore wind farm site. The periods during which the wind resource is good are not supposed to be chosen for maintenance. Therefore, the joint distribution of TWs and WS in 2015 is presented in 
Figure 3. The red line represents the access periods and the green curve represents the wind speed in 2015.

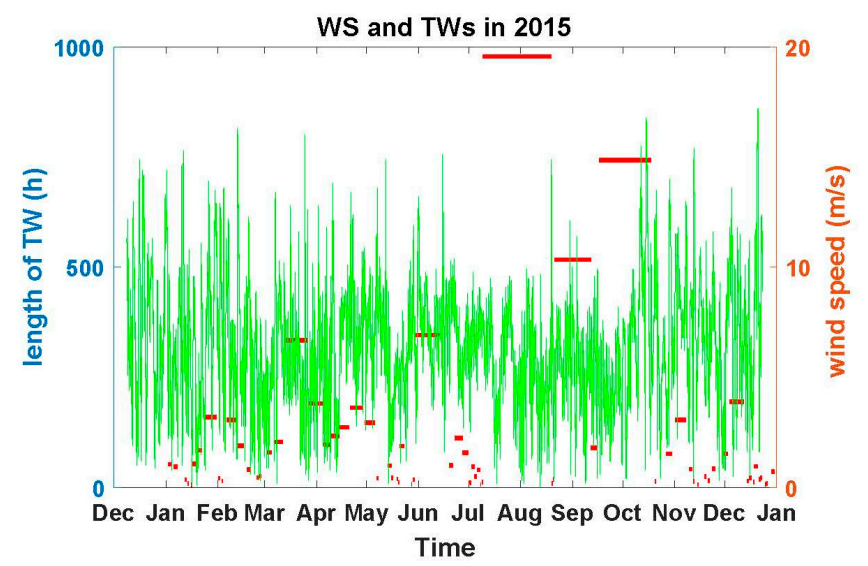

Figure 3. Wind speed and access periods in 2015

It is assumed that the capacity of the wind turbines is 5MW. According to [20], the Cut-In, Rated and Cut-Out wind speeds are $3 \mathrm{~m} / \mathrm{s}, 11.4 \mathrm{~m} / \mathrm{s}, 25 \mathrm{~m} / \mathrm{s}$. Considering the dataset adopted in this work, the maximum wind speed in 2015 is $17.2 \mathrm{~m} / \mathrm{s}$, less than the Cut-Out wind speed. Based on the percentage of maximum wind energy, the classification of wind resource in 2015 is shown in Table 8.

Table 8. Classification of wind resource in 2015

\begin{tabular}{cccc}
\hline Classifications & Percentage of Max WR & WS Range & Grades \\
\hline 1. & $/$ & WS $<3 \mathrm{~m} / \mathrm{s}$ & 0 \\
2. & $2 \%$ to $20 \%$ & $3 \mathrm{~m} / \mathrm{s}<\mathrm{WS}<6.7 \mathrm{~m} / \mathrm{s}$ & 1 \\
3. & $20 \%$ to $40 \%$ & $6.7 \mathrm{~m} / \mathrm{s}<\mathrm{WS}<8.4 \mathrm{~m} / \mathrm{s}$ & 3 \\
4. & $40 \%$ to $60 \%$ & $8.4 \mathrm{~m} / \mathrm{s}<\mathrm{WS}<9.6 \mathrm{~m} / \mathrm{s}$ & 5 \\
5. & $60 \%$ to $80 \%$ & $9.6 \mathrm{~m} / \mathrm{s}<\mathrm{WS}<10.6 \mathrm{~m} / \mathrm{s}$ & 7 \\
6 & $80 \%$ to $100 \%$ & $10.6 \mathrm{~m} / \mathrm{s}<\mathrm{WS}<11.4 \mathrm{~m} / \mathrm{s}$ & 9 \\
7 & $100 \%$ & WS $>11.4 \mathrm{~m} / \mathrm{s}$ & 10 \\
\hline
\end{tabular}

Based on the classification, the WR and TWs in 2015 are displayed in Figure 4. It can be seen that there is a time window in Oct. which is more than 500 hours long. The 5-day averaged wind resource is almost the highest around the year. In this case, maintenance is not recommended unless an anomaly that leads to significant production loss is detected. However, as wind resource level is low in Aug. and Sept., the available time windows in these two months especially the long ones are recommended for scheduled maintenance.

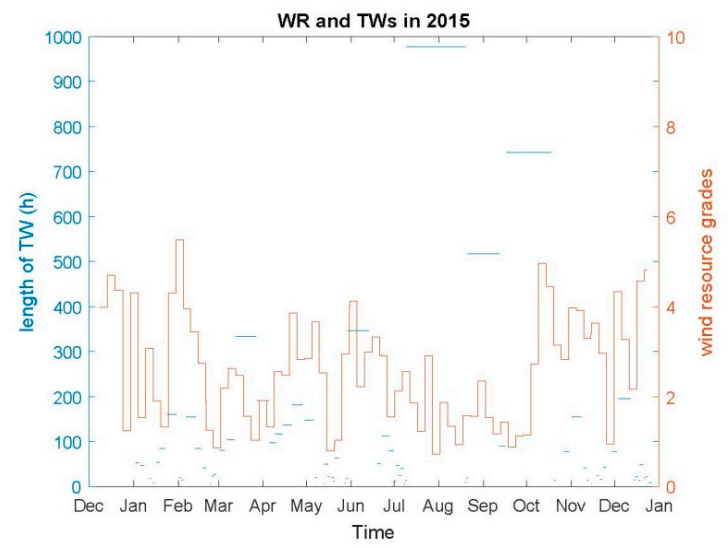

Figure 4. 5-day average wind resource and time windows in 2015

3.3.3 The distribution of access periods over time 
Whether the distribution of access periods over time can be used as reference for maintenance decision making depends on the stability of the data distribution. Hence, the twelve-monthly access rate for 2011 to 2015 is provided in Figure 5. One point that should be clarified here is that the access rate in 2011 and 2014 are almost the same, so the curves overlapped in the figure.

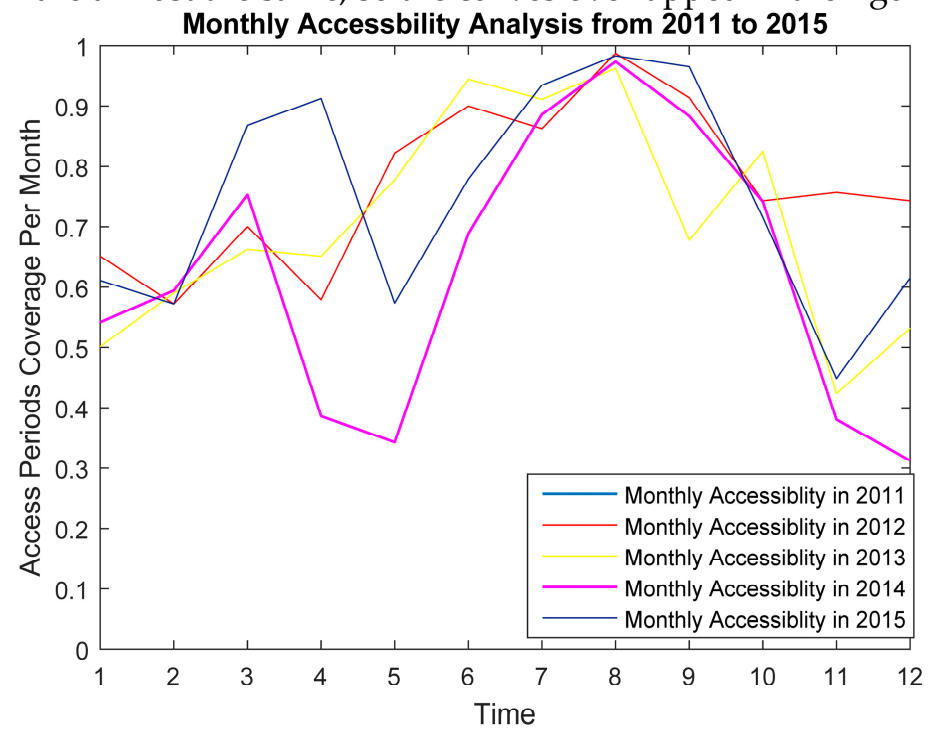

Figure 5. Monthly access periods over time for 2011 to 2015

From Figure 5, it is obvious that access rates from Jul. to Sept. in each year are similar and relatively high. Therefore, maintenance tasks which take long time can be arranged based on the access periods distribution in these two months. To make it more clear, the access periods distribution in 2015 is represented in Figure 6. The longest access period in 2015 in more than two weeks. From Jul. to Sept., the access periods are compact and long enough for overhaul and other long-time maintenance tasks.

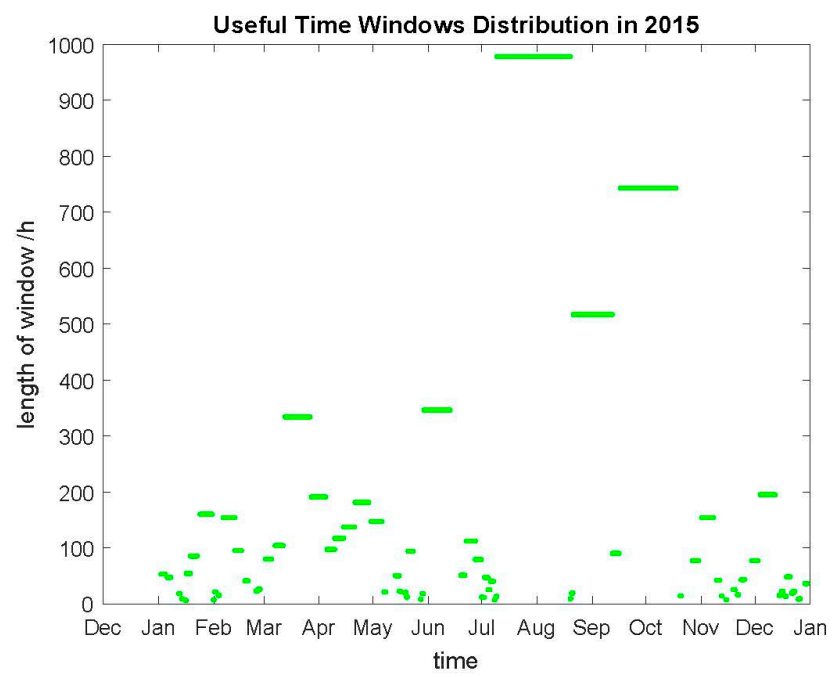

Figure 6. Access periods distribution in 2015 (the green segments represent the access periods no less than 6 hours)

Moreover, when looking further into the distribution of the access periods in each month to provide more detailed information for maintenance decision making, the average waiting time for a useful TW should be studied since it is the average expected interval between two useful TWs. Table 9 shows the accessibility in each month and the information of TWs and WWs. Besides, the composition of the time window series gives a hint on patterns of the useful TWs. And the longer the series is, the more difficult it is to utilize the TWs for maintenance activities. From Table 5, one can also observe that the TWs cover $91.1 \%$ of the whole time in Apr., it is on the same level compared 
with TWs in Jul., Aug. or Sept.. From Figure 2, it can be seen that not very long TWs exist in April, thence, the schedules of maintenance tasks can be divided into several parts to suit the distribution of TWs. Moreover, the 5-year access periods series can be used as input for mathematical assessment of accessibility in section 3.4.

Table 9. Access periods in each month and the composition series of WWs and TWs

\begin{tabular}{|c|c|c|c|c|}
\hline Month & $\begin{array}{c}\text { TWs } \\
\text { coverage }\end{array}$ & $\begin{array}{c}\text { Min/Max } \\
\text { (hr) }\end{array}$ & $\begin{array}{c}\text { Average WW } \\
(\mathrm{hr})\end{array}$ & Time Window series (hr) \\
\hline Jan & $60.0 \%$ & $6 / 100$ & 32 & $35-53-31-47-105-18-24-9-42-6-1-54-1-85-41-100-8$ \\
\hline Feb & $54.2 \%$ & $6 / 155$ & 33 & $\begin{array}{c}10-7-8-21-27-15-55-155-1-85-48-41-70-6-29-23-8- \\
26-74-10\end{array}$ \\
\hline Mar & $86.8 \%$ & $69 / 334$ & 31.7 & 69-48-104-28-334-19-117 \\
\hline Apr & $91.1 \%$ & $73 / 181$ & 12.8 & 73-20-97-1-117-2-137-11-181-30-50 \\
\hline May & $52.1 \%$ & $6 / 96$ & 34.5 & $\begin{array}{c}96-28-21-120-6-8-50-2-22-51-20-3-12-10-64-103-8- \\
14-18-6-57\end{array}$ \\
\hline Jun & $74.9 \%$ & $8 / 288$ & 42.3 & $288-146-51-27-112-2-79-6-8$ \\
\hline Jul & $93.2 \%$ & $6 / 524$ & 7 & $6-13-11-2-47-1-25-8-40-11-7-13-13-1-524$ \\
\hline Aug & $98.1 \%$ & $9 / 453$ & 4.7 & $453-1-9-9-19-4-224$ \\
\hline Sep & $96.5 \%$ & $90 / 312$ & 12.5 & 292-3-90-22-312 \\
\hline Oct & $71.1 \%$ & $14 / 430$ & 104 & $430-59-14-149-67$ \\
\hline Nov & $43.1 \%$ & $7 / 154$ & 51.1 & $9-49-154-42-42-18-14-52-7-88-25-32-16-35-43-93$ \\
\hline Dec & $59.4 \%$ & 6/195 & 25.8 & $\begin{array}{c}8-77-30-195-57-15-15-22-29-13-4-48-22-19-1-22- \\
45-8-13-9-60-6\end{array}$ \\
\hline
\end{tabular}

*(in the composition series, the number in red represents the accessible time window)

\subsubsection{Special weather condition: Dew point}

The dataset used in this work has measurements on dew point temperature, which is considered as the measure of atmospheric moisture. The higher the dew point temperature is, the more moisture in the air can be measured. According to [20], a dew point greater than $20^{\circ} \mathrm{C}$ is considered uncomfortable while greater than $22^{\circ} \mathrm{C}$ is taken as extremely humid. A more detailed classification on dew point temperature is presented in Table 10 based on [21].

Table 10. Dew point, Humidity and corresponding Human Perception

\begin{tabular}{cccc}
\hline Dew point & Human perception & Relative humidity at 32 ${ }^{\circ} \mathrm{C}$ & Alert Level \\
\hline over $26^{\circ} \mathrm{C}$ & Severely high. Even deadly for asthma related illnesses & $73 \%$ and higher & Extreme \\
$24-26^{\circ} \mathrm{C}$ & Extremely uncomfortable, fairly oppressive & $62-72 \%$ & High \\
$21-24^{\circ} \mathrm{C}$ & Very humid, quite uncomfortable & $52-61 \%$ & \\
$18-21{ }^{\circ} \mathrm{C}$ & Somewhat uncomfortable for most people at upper edge & $44-51 \%$ & Moderate \\
$16-18{ }^{\circ} \mathrm{C}$ & OK for most, but all perceive the humidity at upper edge & $37-43 \%$ & \\
$13-16{ }^{\circ} \mathrm{C}$ & Comfortable & $31-36 \%$ & Low \\
$10-12{ }^{\circ} \mathrm{C}$ & Very comfortable & $26-30 \%$ & \\
Under $10{ }^{\circ} \mathrm{C}$ & A bit dry for some & $25 \%$ and lower & \\
\hline
\end{tabular}

Considering safety and health of the technician crews when working under extreme humidity conditions, regulations and warnings are required considering dew point temperature. An insight into the distribution of extreme humidity weather window leads to suggestions for maintenance strategy in a year. Based on the alert level in Table 10, composition of all the working conditions can be divided into four parts, which is shown in Figure 7. 


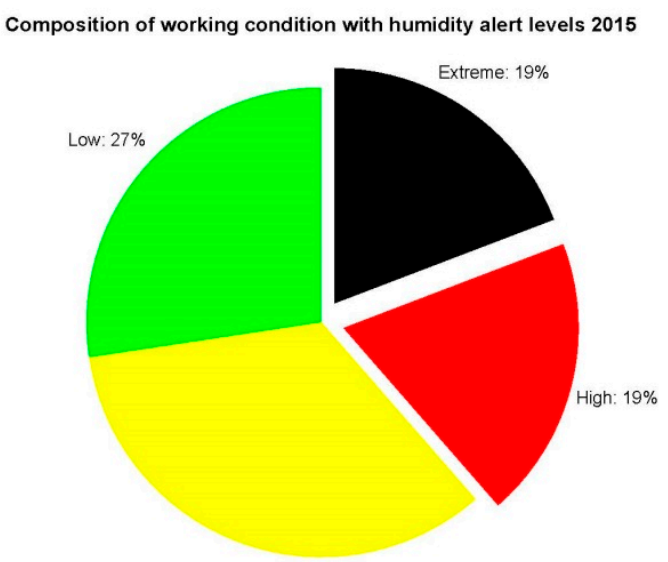

Moderate: $34 \%$

Figure 7. Pie chart of all working conditions in 2015

The percentages of High and Extreme levels are around 38\%. The way this percentage is distributed along time in a year may have impact on accessibility of the offshore site. Hence, the distribution of High and Extreme working conditions are selected and represented in Figure 8.

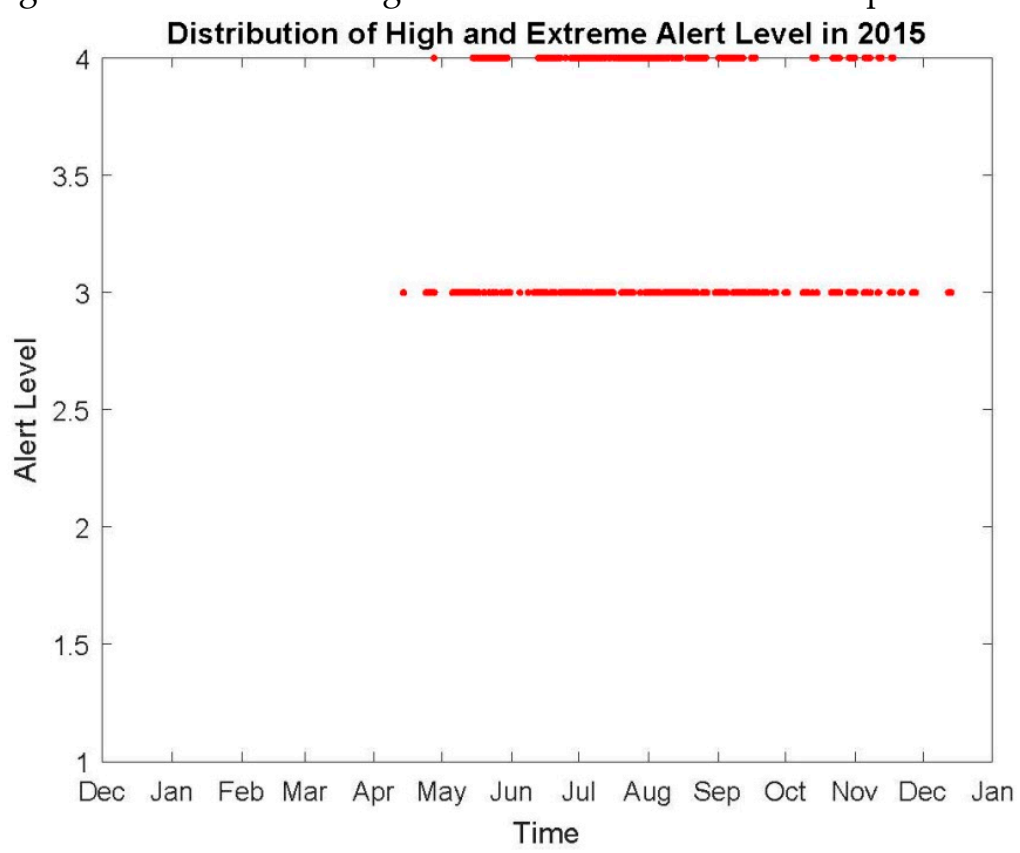

Figure 8. Distribution of High and Extreme level working conditions in 2015

Figure 6 indicates that the humidity in Aug. and Sept. may bring serious health problems to the technicians working in the offshore site. Considering Figure 6, the best time for scheduled maintenance in 2015 is also in these two months. Hence, special medical health care should be prepared for technicians who are supposed to work in the offshore site during these periods. Moreover, for extreme humidity level, the daily work time should be less than that in a normal day.

\subsection{Markov chain based accessibility assessment model}

Based on Table 2, the access periods are divided into 4 states based on their time-length. The criterions are shown in Table 11. Since access periods less than 6 hours are not suitable for offshore maintenance, they are not taken into consideration in this part. The occurrence of each state is shown in Figure 9.

Table 11. Definition of the states for Markov model 


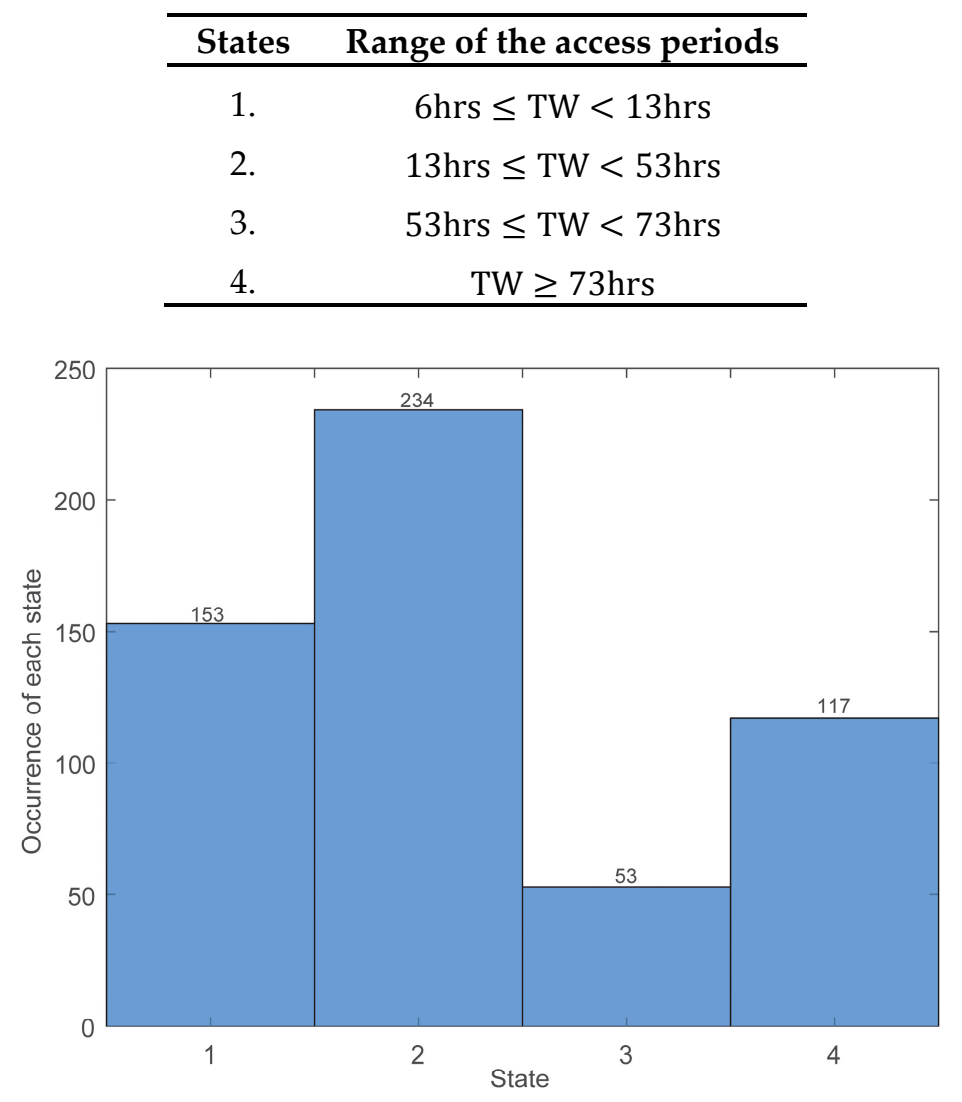

Figure 9. The occurrence of each state based on data from 2011 to 2015

From the calculation of the occurrence of each state, the ISP and TPM of the Markov model based on the 5-year data are displayed in Table 12 and Table 13.

Table 12. ISP calculated with 5 -year access periods

\begin{tabular}{lcccc}
\hline & State 1 & State 2 & State 3 & State 4 \\
\cline { 2 - 5 } Initial Probability & 0.275 & 0.420 & 0.095 & 0.210 \\
\hline
\end{tabular}

Table 13. TPM calculated with 5-year access periods

\begin{tabular}{ccccc}
\hline & State 1 & State 2 & State 3 & State 4 \\
\hline State 1 & 0.296 & 0.428 & 0.138 & 0.138 \\
State 1 & 0.282 & 0.440 & 0.098 & 0.180 \\
State 1 & 0.302 & 0.415 & 0 & 0.283 \\
State 1 & 0.222 & 0.368 & 0.077 & 0.333 \\
\hline
\end{tabular}

In another illustration, Figure 10 displays the Markov model for a 5 -year access periods where the numbers represent transition probabilities among the defined states.

Access periods less than 6 hours are considered as waiting periods in this work. For the Markov model, the average time to expect a transition between two states can be expressed as:

$$
W_{t}=\frac{\sum_{i=1}^{m} T W_{i}+\sum_{j=1}^{n} W W_{j}}{m+n}
$$

where $T W_{i}<6$, $\mathrm{m}$ and $\mathrm{n}$ denote the number of the TWs and WWs. For our data, $W_{t}=32.5$ (hrs).

Based on the method in section 2.3, $P_{k j}, N_{\text {average }}$ and expected waiting time (EWT) for each state can be calculated. The results are shown in Table 14 .

Table 14. Main parameters for accessibility assessment 


\begin{tabular}{|c|c|c|c|}
\hline & $\boldsymbol{P}_{\boldsymbol{k j}}$ & $\boldsymbol{N}_{\text {average }}$ & EWT (hrs) \\
\hline State 1 & 0.194 & 5.161 & 167.7 \\
\hline State 2 & 0.234 & 4.266 & 138.6 \\
\hline State 3 & 0.095 & 10.495 & 341.1 \\
\hline State 4 & 0.141 & 7.121 & 231.4 \\
\hline
\end{tabular}

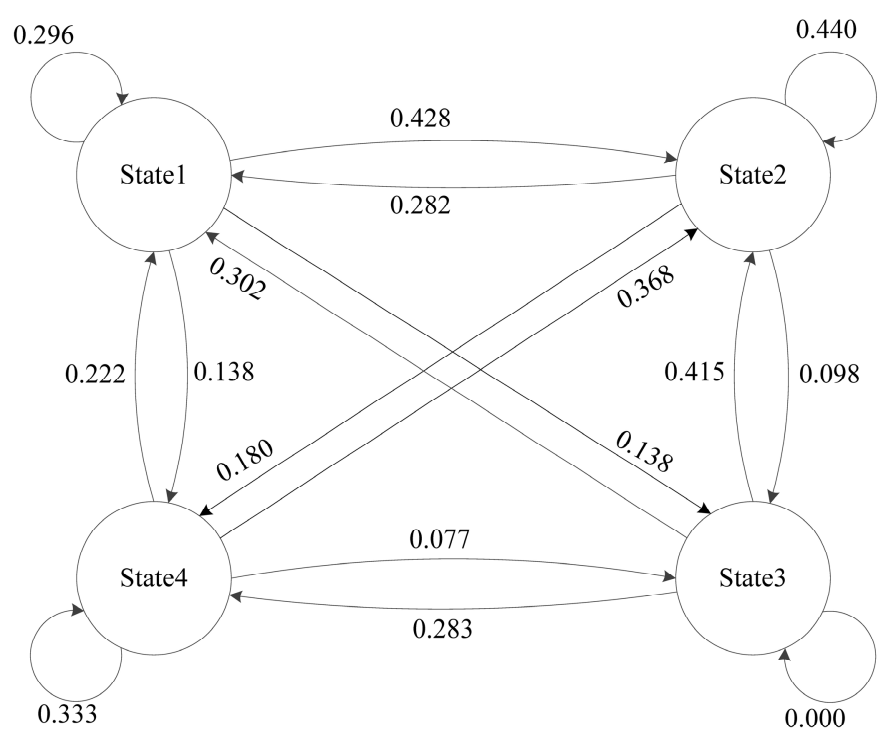

Figure 10. Markov model for access state transition

Based on the Markov model, the expected waiting time for each maintenance type is provided. In [17], the average number of site visits for maintenance of an offshore wind turbine is 72.18 in 40 years. For each maintenance type, the average number is shown in Figure 11.

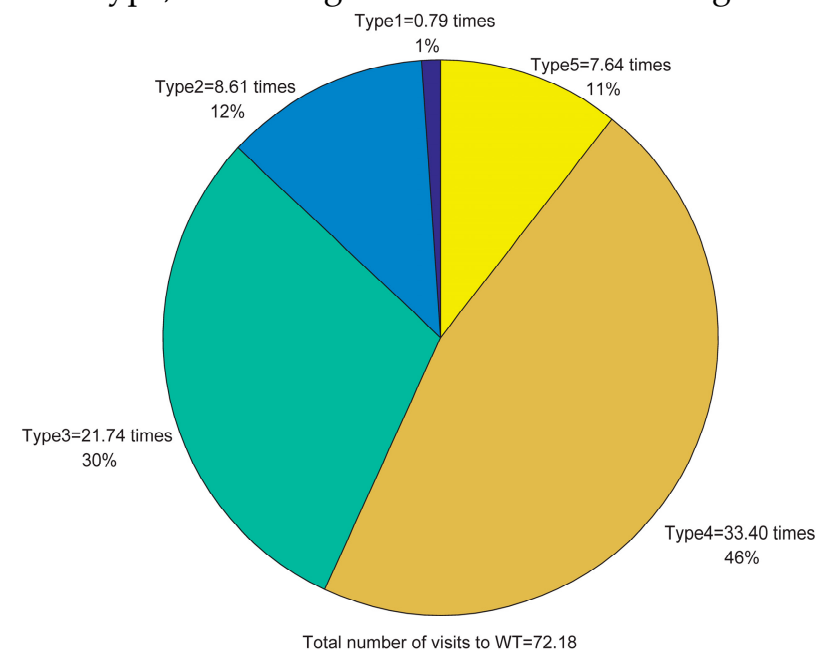

Figure 11. Total number of site visits for maintenance WT in 40 years [17]

Based on Table 2 and Table 14, the expected waiting time for each maintenance type can be acquired. To modelling the production loss due to waiting for appropriated access periods, assumptions should be made. For maintenance type 4 and 5 , the wind turbine is functioning during the maintenance. Then the production loss is depend on wind turbine's performance and the wind speed during that time. Moreover, since the index is created for the whole life time as 40 years, annually averaged data can be used. The production loss due to waiting time then can be expressed as:

$$
E P L=\sum_{i=1}^{5} N_{i} \cdot E W T_{i} \cdot W_{a} \cdot \alpha_{i} \cdot P_{w}
$$


where, EPL is the economic index which represents the expected production loss due to waiting for certain access periods. $N_{i}$ denotes the number of the maintenance types from 1 to $5 . E W T_{i}$ is the expected waiting times for maintenance type i. $W_{a}$ means the annually averaged wind resource for an offshore wind farm. $\alpha_{i}$ is production loss factor for maintenance type $\mathrm{i}$ which equals 1 when $\mathrm{i}$ is 3,4 and 5. $P_{w}$ is the price for electricity from an offshore wind farm. Hence, with the information of all the parameters, EPL can be calculated and used as a reference during the planning stage for site selection.

\section{Conclusions}

In this work, a framework to explore the accessibility of an offshore site is proposed. The framework is constituted of two parts. The first part is a data visualization procedure which is proposed to study the access level of an offshore site for different time scales and perspectives. In the second part, a finite state Markov chain is built to assess the access level in a mathematical way. After applying the framework to a 5-year marine weather data set, some interesting findings can be highlighted. Instead of defining access periods only with wave height, wind resource is taken into account. The results show that, the overhaul or scheduled maintenance should be arranged at the periods with high level accessibility and poor wind resource. For the periods with good wind resource, a helicopter should be used to increase the access level to guarantee the performance of the wind turbines. Moreover, since the prior requirement for marine transportation is safety of the personnel, special weather conditions need more attention. In this data set, dew point based access level and working conditions are studied, and suggestions as medical care and less working time are provided for policy makers. For accessibility assessment, average waiting time for different states are calculated. With more detailed information of maintenance demand of an offshore site, the expected production loss due to time delay can be addressed and used as reference for decision making during planning stage.

Author Contributions: All authors participated in the preparation, research design, method and analysis of this project. All authors discussed and finalized the analysis results to prepare this manuscript.

Conflicts of Interest: The authors declare no conflict of interest.

\section{References}

1. "Global Wind 2015 Report". Global Wind Energy Council (GWEC). Retrieved 2016-04-22.

2. O'Connor, M., T. Lewis, and G. Dalton. "Weather window analysis of Irish west coast wave data with relevance to operations \& maintenance of marine renewables." Renewable energy 52 (2013): 57-66.

3. Martins, D., G. Muraleedharan, and C. Guedes Soares. "Analysis on weather windows defined by significant wave height and wind speed." Renewable Energies Offshore (2015): 91.

4. Martins, D., G. Muraleedharan, and C. Guedes Soares. "Weather window analysis of a site off Portugal." Maritime technology and engineering. London: Taylor \& Francis Group (2015): 1329-1338.

5. Kertesz, Michael, et al. "The role of site accessibility in microRNA target recognition." Nature genetics 39.10 (2007): 1278-1284.

6. Hansen, Walter G. "How accessibility shapes land use." Journal of the American Institute of planners 25.2 (1959): 73-76.

7. Lawrence, Steve, and C. Lee Giles. "Accessibility of information on the web." Nature 400.6740 (1999): 107107.

8. O'Sullivan, David, Alastair Morrison, and John Shearer. "Using desktop GIS for the investigation of accessibility by public transport: an isochrone approach." International Journal of Geographical Information Science 14.1 (2000): 85-104. 
9. Besnard F, Fischer K, Bertling L. A model for the optimization of the maintenance support organization for offshore wind farms. IEEE Trans Sustain Energy 2013; 4(2):443-50.

10. Byon E, Ntaimo L, Ding Y. Optimal maintenance strategies for wind turbine systems under stochastic weather conditions. IEEE Trans Reliab 2010; 59(2): 393-404.

11. Byon E, Ding Y. Season-dependent condition-based maintenance for a wind turbine using a partially observed Markov decision process. IEEE Trans Power Syst 2010; 25(4):1823-34.

12. Irawan, Chandra Ade, et al. "Optimization of maintenance routing and scheduling for offshore wind farms." European Journal of Operational Research (2016).

13. Dalgic, Yalcin, et al. "Advanced logistics planning for offshore wind farm operation and maintenance activities." Ocean Engineering 101 (2015): 211-226.

14. Martini, Michele, et al. "Accessibility assessment for operation and maintenance of offshore wind farms in the North Sea." Wind Energy (2016).

15. Stålhane, Magnus, et al. "Vessel Fleet Optimization for Maintenance Operations at Offshore Wind Farms Under Uncertainty." Energy Procedia 94 (2016): 357-366.

16. Domínguez-Navarro, José Antonio, Iain Dinwoodie, and David McMillan. "Statistical forecasting for offshore wind helicopter operations." Probabilistic Methods Applied to Power Systems (PMAPS), 2014 International Conference on. IEEE, 2014.

17. Le, Bryant, and John Andrews. "Modelling wind turbine degradation and maintenance." Wind Energy (2015).

18. E. Hau and H. Von Renouard, "The Wind Resource," in the wind resource, Springer, 2006, pp. 454-455.

19. National Data Buoy Center, "National Oceanic and Atmospheric Administration," 28 January 2016. [Online]. Available: http://www.ndbc.noaa.gov/. [Accessed 11 April 2016].

20. J. M. Jonkman, S. Butterfield, W. Musial and G. Scott, "Definition of a 5-MW reference wind turbine for offshore system development," National Renewable Energy Laboratory Golden, CO, USA, 2009.

21. J. M. Wallace and P. V. Hobbs, Atmospheric science: an introductory survey, Academic press, 2006.

22. S. Horstmeyer, "Relative Humidity....Relative to What?" Chief Meteorologist, WXIX TV, FOX19, Cincinnati, OH, USA, 15 August 2006. [Online]. Available: http://www.shorstmeyer.com/wxfaqs/humidity/humidity.html. [Accessed 19 April 2016].

23. Rademakers LWMM, Braam H, Zaaijer MB, Van Bussel GJW. Assessment and optimisation of operation and maintenance of offshore wind turbines. In: Proceedings of the European Wind Energy Conference (EWEC), June 16-19, Madrid, Spain; 2003.

24. Utne IB. Maintenance strategies for deep sea offshore wind turbines. J Qual Maint Eng 2010; 16(4):367-81.

25. Dalton GJ, Alcorn R, Lewis T. Operation expenditure costs for wave energy project; O/M, insurance and site rent. In: International conference on ocean energy (ICOE). Bibao, Spain, www.icoe2010bilbao.com; 2010.

26. Walker RT, Johanning L, Parkinson R. Weather windows for device deployment at UK test sites: availability and cost implications, http://www.ewtec.org/; 2011.

27. Vindeby Offshore Wind Farm. (2016, August 21). In Wikipedia, The Free Encyclopedia. Retrieved 17:25, Jan. 13, 2017, from https://en.wikipedia.org/w/index.php?title=Vindeby_Offshore_Wind_Farm\&oldid=735591183

(C) 2017 by the authors; licensee Preprints, Basel, Switzerland. This article is an open access article distributed under the terms and conditions of the Creative Commons by Attribution (CC-BY) license (http://creativecommons.org/licenses/by/4.0/). 